\title{
Produção de Sorbitol por Zymomonas Mobilis ATCC 29191 em Meio de Sacarose Pré-Tratado com Invertase
}

\section{Sorbitol Production By Zymomonas Mobilis ATCC 29191 In Medium Of Sucrose Pre-Treated With Invertase}

\author{
Márcio de Barros ${ }^{1}$; Josiane Alessandra Vignoli²; Viviane Cristina Schiabel ${ }^{2}$; \\ João Batista Buzato ${ }^{3}$; Maria Antonia Pedrine Colabone Celligor ${ }^{3}$
}

\section{Resumo}

\begin{abstract}
Foi estudada a produção de sorbitol em meio de sacarose pré-tratado com invertase, empregando Zymomonas mobilis ATCC 29191. A melhor produção de sorbitol foi 41,39 g/L e a melhor produtividade foi de $1,72 \mathrm{~g} / \mathrm{L} \cdot \mathrm{h}^{-1}$ em 24 horas de fermentação no meio de sacarose pré-tratada. Esses valores representam uma melhoria de $72,17 \%$ na produção de sorbitol com adição de invertase.
\end{abstract}

Palavras-chave: Zymomonas mobilis; sorbitol; invertase

\begin{abstract}
Sorbitol production by Zymomonas mobilis ATCC 29191 in medium of sucrose pre-treated with invertase was studied. The best results were obtained when the medium was pre-treated with invertase as sorbitol production of 41,39 g/L and a productivity of $1,72 \mathrm{~g} / \mathrm{L} \cdot \mathrm{h}^{-1}$ in 24 hours of fermentation. The invertase addition in the fermentation broth increased $72,17 \%$ in the sorbitol formation.
\end{abstract}

Key Words: Zymomonas mobilis; sorbitol; invertase

\section{Introdução}

O uso de sacarose pela bactéria fermentativa Zymomonas mobilis origina subprodutos como sorbitol e levana. O sorbitol é produzido e acumulado como um osmoprotetor a partir da frutose e a enzima bacteriana glicosefrutose-oxirredutase converte glicose e frutose em glicono-ä-lactona e sorbitol respectivamente. Foi demonstrado que a enzima frutoquinase é inibida pela elevação de glicose no meio em decorrência da hidrólise da sacarose e, assim, favorece a conversão da frutose em sorbitol. (BEKERS et al., 2000)

Considerando a ampla aplicação do sorbitol nas indústrias de alimentos e medicamentos com produção industrial de custo elevado, procuram-se alternativas de obtenção de compostos por processos

\footnotetext{
${ }^{1}$ Aluno de Ciências Biológicas, Departamento de Bioquímica - CCE/UEL

${ }^{2}$ Alunas de Mestrado em Ciência e Tecnologia de Alimentos - TAM/UEL

${ }^{3}$ Docente do Departamento de Bioquímica-CCE/UEL. email: macelligoi@uel.br
} 
fermentativos (SILVEIRA; JONAS, 2002). É sabido que Zymomonas mobilis produz sorbitol a partir não só da sacarose, mas também a partir de uma mistura de glicose mais frutose em detrimento da produção de etanol (KANNAN et al., 1998).

Quando uma mistura de glicose mais frutose foi usada para produzir sorbitol, o processo apresentou problemas de aplicação industrial, pois a utilização direta desses substratos gera custo maior comparado com o valor do produto (SPRENGER, 1996).

O uso do tratamento prévio da sacarose por invertase, para a produção de metabólitos de interesse, não tem sido muito explorado e pode ser uma alternativa de diminuição de custo. Sendo assim, este trabalho teve como objetivo, favorecer a produção de sorbitol por Zymomonas mobilis utilizando a hidrólise prévia do meio de sacarose pela invertase de Saccharomyces cerevisiae.

\section{Material e métodos}

Microrganismo e condição de preservação: Zymomonas mobilis ATCC 29191 foi preservada em meio com a seguinte composição (g/\%): sacarose10; extrato de levedura 1,$0 ;\left(\mathrm{NH}_{4}\right)_{2} \mathrm{SO}_{4} 0,2 ; \mathrm{KH}_{2} \mathrm{PO}_{4} 0,3$; $\mathrm{MgSO}_{4} \cdot 7 \mathrm{H}_{2} \mathrm{O} 0,03$; peptona 0,5 e $\mathrm{FeSO}_{4} 0,02$. Após incubação por 24 horas a $30^{\circ} \mathrm{C}$, as culturas foram mantidas a $4^{\circ} \mathrm{C}$ e reativadas a cada 30 dias.

Invertase: A enzima invertase, utilizada para o prétratamento do meio, foi extraída da levedura de panificação, Saccharomyces cerevisiae, segundo Nepomuceno (1998).

Meios de fermentação: Meiol - sacarose a 20\% de açúcares redutores totais (ART) com adição de sais do meio de preservação. Meio II - sacarose $20 \%$ de ART, pré-tratado por 2 horas com invertase, sob agitação, a temperatura de $28^{\circ} \mathrm{C}$, na proporção 1:50 (1 $\mathrm{mL}$ de invertase e $50 \mathrm{~mL}$ de meio de fermentação), este meio também teve a adição dos sais do meio de preservação. Os meios foram esterilizados a $121^{\circ} \mathrm{C}$ por 20 minutos.

Fermentações: $O$ inóculo foi padronizado em 0,2 $\mathrm{g} / \mathrm{L}$ para todos os experimentos. As fermentações foram realizadas em frascos de erlenmeyer de $250 \mathrm{~mL}$, com $100 \mathrm{~mL}$ dos meios I e II. O pH foi ajustado em 6,0 e os frascos incubados por 48 horas a $30^{\circ} \mathrm{C}$. Após os tempos de $0,8,24,32$ e 48 horas amostras foram retiradas para análise do crescimento celular, por densidade ótica, $\mathrm{a}=605 \mathrm{~nm}$. As medidas foram relacionadas com uma curva padrão de peso seco em g/L. Posteriormente, as amostras foram centrifugadas e do sobrenadante foram quantificados os açúcares redutores, redutores totais e o sorbitol.

\section{Determinações dos açúcares redutores (AR) e re-} dutores totais (ART): Pelo método de Somogyi (1945) e Nelson (1944) e os redutores totais segundo Amorim (1982).

Determinação do sorbitol: O sorbitol foi estimado por cromatografia líquida de alta eficiência (CLAE), com coluna aminex HPX-87 (Biorad) $(8 \mathrm{~mm}, 300 \mathrm{X}$ $7.8 \mathrm{~mm}$ ) temperatura de $65^{\circ} \mathrm{C}$ com água destilada e deionizada (ultra pura) no fluxo de $1 \mathrm{~mL} / \mathrm{min}$.

\section{Resultados e discussão}

Muitos esforços têm sido direcionados para substituir processos químicos por processo fermentativo. Industrialmente, o sorbitol é produzido por hidrogenação catalítica de xarope dextrose, em alta temperatura e pressão (RO; KIM, 1991). Quando Zymomonas mobilis é cultivada em meios com alta pressão osmótica, proporcionada através da presença de sais ou altas concentrações de açúcares, a bactéria excreta sorbitol para o meio (BEKERS et al., 2000).

Fermentações por Zymomonas mobilis, podem ocorrer tanto em meio de sacarose como em frutose mais glicose. Entretanto, a fermentação de cada um desses açúcares desenvolve uma resposta metabólica diferenciada. Assim, a utilização de glicose e frutose reduz o tempo de fermentação, enquanto uso de sacarose leva a formação de levana e outros subprodutos, reduzindo a produtividade de etanol. Logo, uma maneira de disponibilizar frutose é adicionar invertase ao meio de sacarose. O pré-tratamento do meio de cultivo rico em sacarose por invertase tem sido usado na produção de ácido lático 
Produção de Sorbitol por Zymomonas M obilis ATCC 29191 em M eio de Sacarose Pré-Tratado com Invertase

\begin{tabular}{cccccccccc}
\hline $\begin{array}{c}\text { CONDIÇÕES DE Tempo } \\
\text { CULTIVO }\end{array}$ & $\begin{array}{c}\text { Ar } \\
\text { (horas) }\end{array}$ & $\begin{array}{c}\text { ART } / \mathbf{L}) \\
(\mathbf{g} / \mathbf{L})\end{array}$ & $\begin{array}{c}\text { Consumo } \\
(\mathbf{g} / \mathbf{L})\end{array}$ & $\begin{array}{c}\text { Sorbitol } \\
(\mathbf{g} / \mathbf{L})\end{array}$ & $\begin{array}{c}\text { Biomassa } \\
(\mathbf{g} / \mathbf{L})\end{array}$ & $\begin{array}{c}\text { Sorbitol } \\
\mathbf{Y p}(\%)\end{array}$ & $\begin{array}{c}\mathbf{Y}(\mathbf{p}) \\
\mathbf{g} / \mathbf{L} . \mathbf{h}^{-\mathbf{1}}\end{array}$ & $\begin{array}{c}\mathbf{Y}(\mathbf{p}) \\
\mathbf{g} / \mathbf{g} \mathbf{l}^{-1}\end{array}$ \\
\hline Meio I & 0 & 40,6 & 211,25 & 0 & 0 & 0,2 & 0 & & \\
Meio I & 24 & 5,68 & 24,26 & 186,99 & 24,04 & 0,8 & 21,19 & 1,0 & 0,11 \\
Meio II & 0 & 147,77 & 211,25 & 0 & 0 & 0,2 & 0 & & \\
Meio II & 24 & 18,27 & 35,05 & 176,2 & 41,39 & 0,52 & 44,01 & 1,72 & 0,23 \\
\hline
\end{tabular}

I (Sacarose sem hidrólise prévia); II (Sacarose com hidrólise prévia)

e etanol com resultados satisfatórios, (OLIVEIRA et al., 2000; GUILMAN et al., 1999/2000).

A tabela 1 mostra os valores de açúcar redutor $(\mathrm{AR})$ 40,6 e 147,77 g/L presentes no meio de cultivo com e sem o tratamento com a invertase, respectivamente. A presença de AR no meio de cultivo antes do tratamento com invertase pode ser explicada a partir da utilização de açúcar cristal comercial usado como fonte de sacarose e da presença desses açúcares na composição do extrato de levedura utilizado. O valor de AR após o tratamento com invertase meio II demonstra uma elevação de $263 \%$ em relação ao meio I.

As figuras 1 e 2 ilustram os parâmetros cinéticos obtidos desde o inóculo até 48 horas de fermentação.

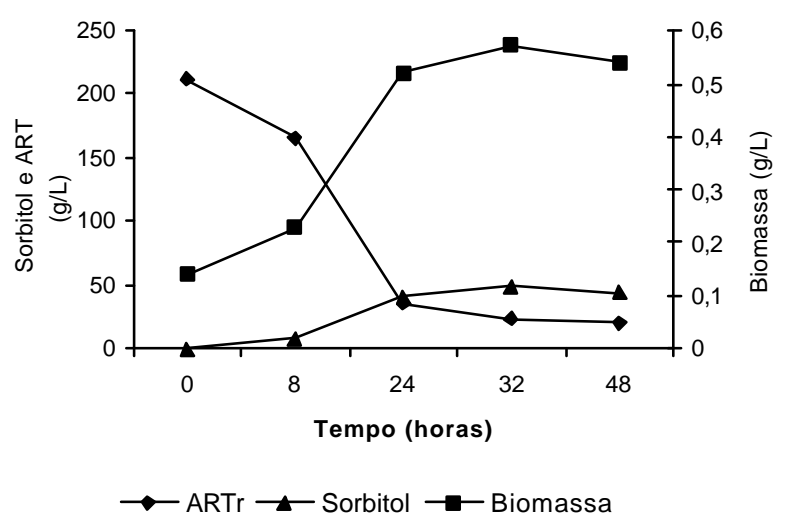

Figura 1. Cinética da produção de sorbitol, açúcares residuais e biomassa de Zymomonas mobilis no meio sacarose $200 \mathrm{~g} / \mathrm{L}$ pré-hidrolisado (meio II).

As figuras mostram que após 24 horas de fermentação os valores analisados permaneceram estáveis, e assim, para cálculo de produção, considerouse este tempo de fermentação.

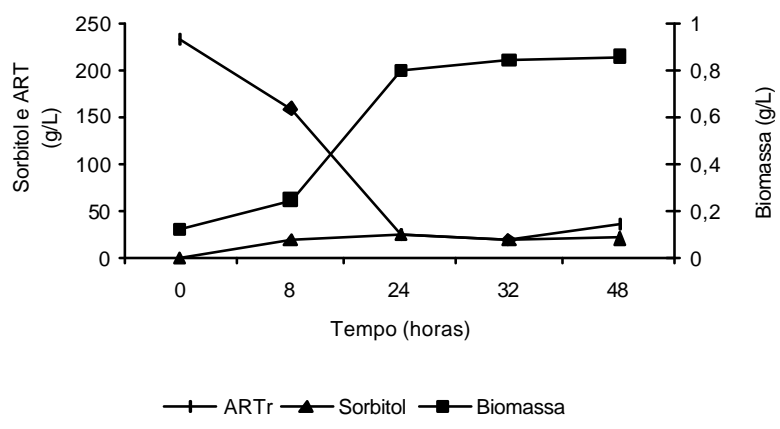

Figura 2. Cinética da produção de sorbitol, açúcares residuais e biomassa de Zymomonas mobilis no meio sacarose $200 \mathrm{~g} / \mathrm{L}$ (meio 1).

Neste trabalho, a produtividade foi de $1,72 \mathrm{~g} / \mathrm{L} \cdot \mathrm{h}^{-1}$ e $1,0 \mathrm{~g} / \mathrm{L} \cdot \mathrm{h}^{-1}$ no meio II e I respectivamente. As concentrações de sorbitol alcançadas foram 24,04 e 41,39 $\mathrm{g} / \mathrm{L}$ nas condições I e II respectivamente. Isto representa uma elevação de $72 \%$ quando é feito o tratamento do meio com invertase. Lee e Huang (1995) utilizaram invertase imobilizada e Zymomonas mobilis, para a produção de etanol e sorbitol. As concentrações de sorbitol variaram de 5 a $24 \mathrm{~g} / \mathrm{L}$ sem invertase e 15,7 a 33,4 g/L com invertase imobilizada. A utilização de mutantes com alta atividade de levanasacarase em meio de sacarose a $100 \mathrm{~g} / \mathrm{L}$, foi estudados por Kannan et. al. (1997, 1998). Os resultados para a produção de sorbitol não foram satisfatórios, uma vez que as concentrações atingidas foram 1,8; 1,3 e 7,4 g/L com os mutantes denominados de LS1A; LS1 e B-806, respectivamente.

Contudo, Kirk e Doelle (1993) usaram uma linhagem mutante, sem a atividade da frutoquinase e juntamente com invertase imobilizada, e alcançaram 17,3g/L de sorbitol em apenas 5 horas de fermentação. 
Neste trabalho, os valores de conversão de substrato e sorbitol foram $0,11 \mathrm{e} 0,23 \mathrm{~g} / \mathrm{g} \cdot \mathrm{h}^{-1}$ no meio I e II respectivamente. Silveira et al. (1992) utilizaram uma mistura equimolar de glicose e frutose na concentração final de $100 \mathrm{~g} / \mathrm{L}$ e o valor foi de $0,11 \mathrm{~g} /$ g. $\mathrm{h}^{-1}$ por esta mesma cepa.

Os resultados apresentados neste trabalho, utilizando o pré-tratamento com invertase do meio de fermentação, mostraram favoráveis à produção de sorbitol por Zymomonas mobilis.

\section{Conclusões}

A partir dos resultados, verifica-se que a préhidrólise da sacarose do meio de fermentação, pela invertase de levedura aumentou a disponibilidade de açúcares redutores, com conseqüente aumento da produção de sorbitol por Zymomonas mobilis.

A melhor condição para a produção de sorbitol foi no meio de sacarose pré-hidrolisado com invertase elevando a produção em 72,17\% comparando - se ao meio sem pré hidrolise da sacarose.

A melhor produtividade foi em 24horas de fermentação atingindo $1,72 \mathrm{~g} / \mathrm{L} \cdot \mathrm{h}^{-1}$. Assim, esta técnica pode representar uma alternativa viável para melhorar a produção de sorbitol, sem onerar o processo em meio de sacarose por Zymomonas mobilis.

\section{Referências}

AMORIM, H. V.; ZAGO, E. A.; OLIVEIRA, A. J. Novos métodos analíticos para controle de fermentação alcoólica. São Paulo: Sociedade Brasileira de Microbiologia, 1982. (Série: Manuais de Técnicos e Científicos)

BEKERS; M. et al. The effect of osmo-induced stress on product formation by Zymomonas Mobilis on sucrose. International Journal of Food Microbiology, v. 55, p.147150,2000

DOELLE, H. W. et al. Zymomonas mobilis : Science and industrial application. Critical Reviews in Biotechnology, v.13, n.1, p.57-98, 1993.

GUILMAN, F.; BUZATO, J. B.; CELliGOI, M. A. P. C. Comparação da produção de etanol por Zymomonas mobilis em meio melaço de cana-de-açúcar puro e pré- tratado com invertase. Semina: Ciências Biológicas / Saúde, Londrina, v. 20/21, n.2, p.39-43, jun. 1999/2000.

KANNAN, T.R.; SANGILIYANDI, G.; GUNASEKARAN, P. Influence of intra-and extracellular sucrases of Zymomonas mobilis on the ethanol production and by - product formation. Biotechnology Letters, v.19, n.7, p.661-664, 1997.

KANNAN, T. R.; SANGILIYANDI, G.; GUNASEKARAN, P. Improved ethanol production from sucrose by a mutant of Zymomonas mobilis lacking sucrases in immobilized cell fermentation. Enzyme and Microbial Technology, v.22, p.179-184, 1998.

KIRK, L. A.; DOELLE, H. W. Rapid ethanol production from sucrose without by product formation. Biotechnology and Bioengineering, v.15, n.9, p.859-990, 1993.

LEE. W. C; HUANG. C. T. Enhancement of ethanol production from sucrose by Zymomonas mobilis by the addition of immobilized invertase. Enzyme and Microbial Technology, v.17, p.79-84, 1995.

NELSON, N. A photometric adaptation of the Somogyi method for determination of glucose. Biochemistry, v.53, p.375-380, 1944.

NEPOMUCENO, M. F. Cinética enzimática II da invertase. In: Bioquímica experimental. Piracicaba; UNIMEP, 1998. p. 57-60.

OLIVEIRA, A. R. de et al. Produção de ácido lático por Lactobacillus curvatus, em fermentação contínua, utilizando melaço de cana-de-açúcar previamente tratado com invertase. UNOPAR Científica, Ciências Biológicas e Saúde, Londrina, v.2, n.1, p.9-5, out. 2000.

ROH, H. S.; KIM, H. S. Continuous production of gluconic acid and sorbitol from sucrose using invertase and an oxirredutase of Zymomonas mobilis. Enzyme Microbiology and Technology, v.13, p.920-924, 1991.

SILVEIRA, M. M. et al. Production of sorbitol and gluconic acid by Zymomonas mobilis: comparison of strains. Arquivos de Biologia e Tecnologia, v.35, p.591594, 1992.

SILVEIRA, M. M.; JONAS, R. The biotechnological production of sorbitol. Applied Microbiology an Biotechnology, v.59, p.400-408, 2002.

SOMOGYI, M. A. A new reagent for determination of sugar. Journal Biology Chemistry, v.160, p.61-68, 1945.

SPRENGER, G. A. Carbohydrate metabolism in Zymomonas mobilis: a catabolic highway with some scenic routes. FEMS: Microbiology Letters, v.145, p.301307, 1996. 